\title{
ENTREVISTA COM VERÓNICA HOLLMAN
}

Verónica Hollman é licenciada em Geografía pela Universidad Nacional del Comahue, Argentina. Master of Arts pela University of British Columbia (Canadá). Doutora em Ciências Sociales pela FLACSO (Facultad Latinoamericana de Ciencias Sociales). Atualmente é Investigadora Adjunta do CONICET (Consejo Nacional de Investigaciones Científicas y Técnicas/Argentina) com Sede de trabalho no Instituto de Geografía "Romualdo Ardissone", Facultad de Filosofía y Letras, Universidad de Buenos Aires. Suas pesquisas analisam as relações entre cultura visual e a construção de imaginários geográficos. Proferiu a conferência "Imagem (da), (na), (como) fronteira" no encerramento do III Simpósio Internacional/IV Simpósio Nacional Geografia, Literatura e Arte (SIGEOLITERART).

\section{Entrevista realizada por Flaviana Gasparotti Nunes}

Entre-Lugar - Conte-nos um pouco sobre suas origens familiares e como a sua história se desdobrou no fazer Geografia. Como começou a trabalhar com esse conhecimento e como se entende actualmente no contexto da academia argentina?

Verónica Hollman: Mi historia familiar se ha construido “entre lugares” en más de un sentido. Sin remontarme a mis bisabuelos que vinieron de Europa, tempranamente tuve la experiencia directa de vivir en un lugar y tener afectos en varios lugares. Mis padres, siendo muy jóvenes, emigraron de su ciudad natal, localizada en el nordeste de Argentina. Tenían trabajo en su ciudad, sin embargo relatan que deseaban horizontes para sus hijos que no vislumbraban en su ciudad natal. En rigor comenzaron su itinerario migratorio cuando los hijos todavía éramos un proyecto con primer destino en el noroeste de Argentina: allí mi padre trabajó en dos ingenios azucareros. Mi único hermano nació allí. Desde el noroeste argentino la familia siguió hasta la Patagónia en una ciudad llamada El Chocón que fue creada en torno a una represa hidroeléctrica. Una ciudad creada íntegramente por una empresa estatal en el medio de la estepa patagónica - con escuela, supermercado, club, hospital, cine, casas y hasta iglesia. La ciudad tenía dos partes: una villa temporaria que albergaba a los operarios que trabajaron en la construcción y puesta en marcha de la represa y una villa permanente para la población empleada en la operación de la central. Nací y viví mi primera infancia en esa villa permanente pues mi padre fue a trabajar cuando la central hidroeléctrica comenzó sus operaciones y mi madre, algunos años más tarde, comenzó a trabajar como maestra en la escuela primaria. Se trataba de una ciudad- empresa donde las diferencias sociales se definían en torno al rol que cada empleado desempeńaba en la empresa. Probablemente el mejor indicador de aquellas distinciones haya sido el barrio de residencia que era asignado a cada empleado en función de su jerarquía en la empresa. Cuando tenía cinco años mi familia siguió su itinerario a la ciudad de Neuquén, localizada en el norte de la Patagonia y a unos $80 \mathrm{kms}$ de El Chocón. Mis padres se habían propuesto vivir en una ciudad más grande antes de 
que comenzáramos nuestra educación secundaria con el propósito de que tuviéramos más opciones y oportunidades a nivel educativo. Viví en la ciudad de Neuquén hasta terminar mis estudios universitarios, sin embargo toda mi niñez y adolescencia se trazó entre el lugar de origen de mis padres, donde vivían mis abuelos, tíos y primos a quienes por otra parte visitábamos muchas veces en el ańo, y Neuquén, el lugar del trabajo de mis padres, de mi escuela y de los afectos no sanguíneos. Tal vez lo más interesante sea que esa experiencia era compartida con gran parte de mis compañeros de escuela que también tenían a sus familiares en otras provincias de Argentina porque Neuquén es una ciudad de inmigrantes internos desde mediados de la década de 1960.

Decía que tempranamente tuve la experiencia de "entre lugares" también porque recuerdo que en cada viaje desde Neuquén o Paraná, la ciudad de mis abuelos, me encantaba imaginar la vida de la gente en cada lugar que veía desde la ventanilla del auto: cómo sería ir a la escuela, al club, al supermercado, andar en bicicleta, etcétera. Imaginar esas múltiples cotidianeidads y su simultaneidad funcionaba como un juego que mitigaba las horas de viaje que requería recorrer más de $1500 \mathrm{kms}$. La experiencia de viajes familiares seguramente también fue moldeando mi modo de vivir los lugares. Desde pequeńa tuve la experiencia de viajar no solo para visitar a la familia sino también para conocer la región donde vivía. Mis padres siempre fueron muy viajeros y desde pequeños nos llevaron a hacer campamentos y caminatas en la región de los lagos del sur de la provincia de Neuquén y Río Negro. Subir al auto un viernes a la tarde y hacer $500 \mathrm{kms}$ hasta algún lugar de los lagos de la Patagônia para hacer caminatas durante el fin de semana fue algo bastante habitual en mi niñez y adolescencia. Transitar senderos a los cuales solo se podía llegar caminando, armar una carpa en lugares que parecían inexplorados fueron construyendo otros afectos, me refiero a afectos a los lugares y que de algún modo expresaba, cada vez que regresábamos a casa, despidiéndome de "mis montañas".

Pienso que la experiencia migratoria de mis padres de algún modo se desdobló en dos búsquedas personales que todavía persisten. Por un lado en mi propio deseo de hacer la experiencia de vivir en otros lugares: siempre siento que conocer un lugar significa crear lazos con personas y rincones o fragmentos de ese lugar, un proceso que, sin duda, requiere tiempo. Ya he vivido en varias ciudades y, aunque desde hace algunos años siento que Buenos Aires es mi ciudad, nunca renuncio a vivir algún tiempo en otro lugar. Por otro lado, desde hace varios años vengo trabajando la relación entre geografía y cultura visual. Creo que esta línea de investigación se enlaza tanto a aquella experiencia visual que fui cultivando desde la ventanilla del auto como a otra que excede lo visual. Caminar en la montańa te pone en contacto también con los límites de la experiencia visual o, mejor dicho, la conecta con otras sensibilidades no estrictamente visuales.

\section{Entre-Lugar - Como analisa a sua evolução intelectual em relação as mudanças que ocorreram na Geografia a partir dos anos 1970?}

Verónica Hollman: Hice mi carrera de grado en la Universidad Nacional del Comahue en la primera década de los años 1990. Estudié en un período de consolidación de las Geografías Críticas en las universidades de América Latina, con gran influencia de la 
geografía producida en la Universidad de São Paulo. El departamento de Geografía de mi universidad tuvo una temprana relación con geógrafos críticos, relación que se gestó en el II Encuentro Latinoamericano de la Nueva Geografía de 1974 en Neuquén. Por entonces el director del departamento de Geografía de la Universidad del Comahue era un geógrafo uruguayo que promovió los vínculos con otros geógrafos latinoamericanos. De modo que a pesar de la lejanía física que existía con respecto a otras universidades más antiguas y también más centrales en la producción intelectual en Argentina, mis profesores estuvieron muy marcados por aquel encuentro en el que participaron más de 200 geógrafos y que por otra parte funcionó como antesala de lo que serían los encuentros de geógrafos latinoamericanos. Cierto es que la dictadura militar iniciada en 1976, frenó aquel movimiento. Sin embargo, no logró quebrar las relaciones que allí comenzaron a gestarse entre geógrafos latinoamericanos y que con el retorno democrático se recuperarían e intensificarían.

En mi formación de grado era recurrente la crítica a la geografía cuantitativa, presentada casi como sinónimo de la geografía anglosajona. Creo que en mi desarrollo intelectual han sido muy importantes dos recorridos posteriores a mi formación de grado. El primero ha sido conocer desde el ámbito anglosajón propiamente dicho otras geografías críticas con más anclaje cultural y a su vez menos apegadas al marxismo. Hacer la maestría en una universidad canadiense me permitió abrirme a otras lecturas y conocer otras corrientes de pensamiento geográfico dentro de la geografía anglosajona. El segundo, pensar la disciplina desde otras disciplinas, sobre todo desde la sociología de la disciplina y desde la educación. De hecho, llegué a muchas de mis preguntas actuales de investigación en esta apertura hacia lecturas de otras ciencias sociales.

\section{Entre-Lugar - Quais pensadores e/ou textos você entende como fundamentais para sua formação e evoluçáo intelectual?}

Verónica Hollman: Ingresé a la línea de investigación que vengo trabajando en los últimos diez años desde el campo de la historia de la educación. Los trabajos de Inés Dussel fueron claves para pensar las disciplinas, también la geografía, como órdenes visuales. Para mi sorpresa y de modo bastante fortuito encontré un artículo de Gillian Rose publicado en la Revista Antipode junto a una serie de intervenciones de otros geógrafos que discutían la condición visual de la geografía. Aquel grupo de artículos (y la bibliografía que allí se citaba) se convirtió en una preciosa llave para abrir un cofre de literatura sumamente rica, desafiante y sólida sobre la relación entre geografía y visión. Particularmente los trabajos de Denis Cosgrove, condensados magistralmente en su libro Geography \& Vision, han sido sumamente inspiradores para pensar nuevas preguntas sobre lo visual en la producción, difusión y enseñanza del conocimiento geográfico. Otro libro que fue clave para mi fue Picturing Place: Photography and the Geographical Imagination editado por Joan Schwartz y James Ryan. Desde el campo de los estudios visuales, las obras de Nicholas Mirzoeff me permitieron pensar en lo visual más allá de la imagen. Una serie de trabajos que provienen de la historia del arte siguen ayudándome a pensar las imágenes desde su propia complejidad particularmente los trabajos de George Didi-Huberman, Susan Sontang, John Berger 
y Philippe Dubois entre otros. También han sido claves trabajos de colegas geógrafos contemporáneos como Wenceslao Machado Oliveira Jr, Jorn Seeman, Gisele Girardi, Carla Lois, Valéria Cazetta y André Novaes. Muchos de ellos trabajan las imágenes en relación a la enseñanza de la geografía (en la escuela y por fuera de ella). Otro campo de literatura que me sigue provocando preguntas interesantes es el de la historia de la ciencia, particularmente los trabajos de Lorraine Daston, Peter Galison y recientemente un libro de Sonja Dümpelmann. Pienso que muchos interrogantes de investigación surgieron a partir mi mayor disposición a encontrarme con imágenes en las variadas e innumerables exposiciones que se presentan en Buenos Aires. En los últimos años he experimentado que las imágenes pueden provocar el pensamiento!

Entre-Lugar - Como analisa a situação da geografia produzida na Universidade argentina hoje?

Verónica Hollman: La comunidad de geógrafos en Argentina es mucho más reducida que la de Brasil y esto más allá de la cuestión numérica repercute en la producción científica, sobre todo en la conformación, crecimiento y consolidación de grupos de investigación en las universidades y en centros de investigación que funcionan allí. En los últimos años, sin embargo, la producción geográfica ha aumentado de la mano de una política de promoción de la formación de doctores y de fortalecimiento del sistema científico. Las investigaciones doctorales y pos-doctorales, con el apoyo de becas de formación de pos-grado, sin duda han contribuido a ampliar la agenda de investigación en la geografía argentina y profundizar temáticas que ya se venían trabajando. Claro que esto lleva muchos ańos porque la consolidación de grupos de investigación es la clave para el desarrollo de los campos científicos. No se avanza con trabajos de investigación individuales, sino por lo contrario a partir de la conformación de grupos y redes de investigación. Con tristeza y desasosiego digo que existen demasiados indicios de que este ciclo se ha terminado: recortes en la cantidad de becas, en el número de investigadores en el principal organismo de investigación de Argentina que es el CONICET, en los presupuestos de los organismos de ciencia y técnica, así como en las universidades. ¿Cómo podremos conformar grupos de investigación si cada vez hay menos becarios doctorales o si los doctores no encuentran aquí posibilidades para seguir desarrollando sus líneas de investigación? El panorama es bastante sombrío también en términos regionales. Señalo esto porque no es un dato menor otro proceso interesante que se dio en los últimos diez años a nivel regional. Me refiero a la consolidación e institucionalización de programas y redes de investigación entre investigadores argentinos y brasileños que ha permitido no solo aunar esfuerzos en líneas de investigación, sino también pensar nuestras realidades desde estas redes de investigación gestadas, promovidas y sostenidas regionalmente.

\section{Entre-Lugar - Você consegue estabelecer comparaçóes entre as mudanças ocorri- das na Geografia praticada nas academias argentina e a brasileira? \\ Verónica Hollman: Creo que en los últimos cuarenta años las geografías practicadas en argentina han estado muy ligadas a las practicadas en Brasil. Podría decir que ambas}


danzan con ritmo y bastante sincronía. Enfatizo el plural porque me parece que sería pertinente explicitar que existen varias geografías en cada uno de los campos académicos en cuestión. Tal vez en un primer período ese vínculo ha sido más fuerte con la geografía desarrollada en la Universidad de São Paulo, a través de lazos personales e institucionales que se fueron tejiendo entre ese centro de estudios y la Universidad de Buenos Aires, la Universidad del Sur y la Universidad del Comahue. Desde mi carrera de grado en la Universidad Nacional del Comahue tuve la posibilidad de leer textos de geógrafos brasileños, también escucharlos cuando visitaban mi universidad. Incluso esta relación tan fuerte con la literatura geográfica brasileña funcionó como una (claro que no fue la única) de las motivaciones para que me decidiera a estudiar portugués.

Sin duda, el movimiento de geografías críticas ha sido contemporáneo para las geografías académicas de Argentina y de Brasil. Han compartido sus análisis críticos a las geografías hegemónicas, preocupaciones y agendas de investigación. También existe cierta sincronía con la consolidación institucional de geógrafos críticos en las universidades.

En los últimos años veo que existen más vinculaciones con geografías desarrolladas en otras universidades de Brasil. También se han consolidado redes temáticas entre geógrafos argentinos y brasileños. Esto me parece que por un lado expone el crecimiento del campo disciplinar en Brasil más allá de algunos centros de investigación históricos; por otra muestra que las redes de investigación se han vuelto más amplias, complejas y diversas. $\mathrm{Y}$ esto me parece de gran riqueza para el campo disciplinar, aunque todavía tan solo podemos entrever el impacto de estas redes.

\section{Entre-Lugar - E a geografia praticada no ensino básico na Argentina, como se en- contra em relaçáo a essa elaborada nos centros universitários?}

Verónica Hollman: Considero que la geografía escolar, la geografía de la enseñanza básica y media, tiene un código disciplinar que se ha ido configurando en la propia institución escolar y de manera bastante autónoma a la geografía elaborada en los centros universitarios. En mi trabajo de investigación doctoral pude comprobar que, en la construcción del contenido de la disciplina, no sólo se pone en juego el referencial geográfico (como sistema de referencia de los profesores) y la cultura disciplinar personal, sino que también desempeña un rol clave el modo de entender la disciplina de cada comunidad escolar y la posición de cada profesor en ésta. La perdurabilidad de un esquema de estructuración de los contenidos, que atraviesa la geografía escolar en diferentes momentos históricos funciona como un conjunto de reglas prácticas que permiten organizar en forma homogénea lo que se entiende por geografía en la escuela y a la vez, clasificar nuevos contenidos como geográficos/no geográficos. Es decir, constituye un instrumento que permite clasificar, ordenar contenidos y marcar la permanencia de los profesores en el territorio que se considera exclusivo de la disciplina.

Esta autonomía relativa se evidenció también la producción de materiales escolares escritos en la década de los años 1990. Un número importante de esos libros escolares se adelantaron a discusiones y a investigaciones que posteriormente se comenzarían a 
desarrollar en la geografía académica. El concepto de transposición didáctica se pone en jaque en la experiencia más reciente (aunque no solo en este período si tenemos en cuenta que la geografía escolar antecedió la constitución de un campo disciplinar académico) porque la renovación de los materiales didácticos de los años 90 se adelantó a la producción académica. Tal vez porque en la producción de esos materiales didácticos participaron geógrafos jóvenes que por ese entonces no tenían una posición consolidada en la geografía académica. También en mi investigación doctoral encontré que en la escuela se dan creaciones muy interesantes y originales que otorgan un entramado propio y particular a la geografía escolar. En resumen, para mí no es un punto problemático el hecho de que la geografía escolar sea relativamente autónoma de la geografía académica. Lo que sí, en cambio, me parece problemático es la perdurabilidad de la idea, a modo de imperativo, de que solo se pueden generar formas "correctas" de enseñar el conocimiento científico en las escuelas desde el campo académico. Todavía no se acepta que la geografía escolar y la geografía académica pueden ser mundos muy distintos y realidades muy diferentes, con todas las potencialidades que esto puede abrir.

\section{Entre-Lugar - Quais são os principais desafios para a produçáo científica da geo- grafia hoje no Brasil e na Argentina?}

Verónica Hollman: Creo que el principal desafío que se nos presenta hoy tanto en Brasil como en Argentina es leer, interpretar y enfrentar los tiempos neoliberales que vuelve a atravesar América Latina. Estos tiempos nos han mostrado el poder que tienen los medios de comunicación para crear relatos, sumamente cuestionables, y convertirlos en sentido común. La geografía y todas las ciencias sociales tienen el desafío y la obligación de cuestionar estos relatos, de mostrar sus debilidades, inconsistencias. Me parece que es una (seguramente no la única) de las claves para articular escenarios otros que sean integradores, solidarios, inclusivos y creativos.

Entre-Lugar - A Universidade Federal da Grande Dourados (UFGD) está localizada próxima à fronteira entre Brasil, Paraguai e Bolívia, daí discutirmos o conceito de Entre-Lugar como esse território de encontros e tensóes em que a multiplicidade acontece com toda a sua singularidade. Como pensa esse conceito?

Verónica Hollman: No es un concepto que hasta el momento haya trabajado en mis investigaciones. Sin embargo, me parece que la mayor contribución de este concepto es desestabilizar las divisiones binarias y mostrar la riqueza de la hibridez, de la fricción. En otras palabras, nos fuerza a prestar atención a las tensiones que existen en distintos niveles (empíricos, analíticos, teóricos) ante divisiones binarias. En este sentido, considero que los estudios de áreas de frontera al desplegar la complejidad de esos espacios en sus múltiples aspectos están realizando valiosas contribuciones a las Ciencias Sociales. La geografía, como disciplina de la modernidad, tiene una tendencia recurrente a pensar en términos binarios: este-oeste, natural-social, físico-humano, objetivo-subjetivo, rural-urbano y podría seguir acrecentando esta lista. No obstante, la contemporaneidad desestabiliza 
empíricamente estos polos binarios y este contexto hace que sea todavía más importante contar con conceptos que nos fuercen a colocar la lupa en los matices. En mi línea de investigación creo que el concepto de entrelugar podría permitir pensar los matices del binario imaginario-real/ ficción-real. A propósito de desestabilizar este binario y mostrar sus "entre-lugares" para mi fue clave un libro sobre cine titulado Ficciones de lo real. A su vez, creo que las imágenes son un "entre lugar": muestran e invisibilizan, presentan, pero también crean realidades. Problematizar las imágenes en la geografía podría funcionar como entrelugares para estas y otras fronteras que la disciplina se han empeñado en crear, fomentar y sostener.

Entre-Lugar - ¿Es possible El sur? Pensando a partir de Boaventura de Souza Santos, você acredita que é possível um conhecimento científico alternativo a partir dos saberes presentes nas diversas práticas sociais que acontecem em situaçóes periféricas, marginais, sejam estas na Argentina ou nas fronteiras do Brasil, ou só é possível um modelo de ciência e ela náo depende da diversidade sociocultural?

Verónica Hollman: Existen interrogantes que atraviesan la ciencia tanto en el centro como en las periferias. También otros que son específicos y que, por ende, se despliegan de manera única en los márgenes. La ciencia es una producción sociocultural y esto significa que es moldeada por el contexto en el que se produce, en sus preocupaciones, temáticas de interés, metodologías, conexiones y redes. Entonces, sin duda, tenemos mucho para aportar desde nuestras realidades: pensar el mundo desde estos márgenes. Si me permiten utilizar una analogía muy visual diría que en cada toma fotográfica podemos hacer distintos encuadres. Cada encuadre tendrá efectos en la imagen producida y por ende en lo que miraremos al encontrarnos con ella: quedarán afuera algunas cosas y otras no. La ciencia funcionaría como esa cámara fotográfica ante el ojo (y el dedo) del fotógrafo que acciona el obturador y lo fotografiado. Creo que el lugar y el tiempo en el cual hacemos ciencia hace que pongamos nuestro ojo y la cámara en distintas posiciones y que por ende consigamos distintos puntos de vista. No obstante, la producción científica de los márgenes también tiene que tener un lado universalista: no puede aislarse. Tal vez lo que está ocurriendo en algunos congresos internacionales en torno a los idiomas nos da algunas claves para ponderar el diálogo local/universal y sobre todo los intersticios. Cada vez es más frecuente que se acepten varios idiomas como lenguas oficiales de los congresos y en la mayoría de los casos sin traducción simultánea. Esto significa que cuantos más idiomas podamos entender y todavía mejor hablar, más posibilidades tendremos de dialogar con colegas, sin estar mediados por los filtros que impone comunicarse en un solo idioma. Volviendo a la analogía visual: tendremos más puntos de vista, y además puntos de vista bien diferentes. En los márgenes tenemos una mayor tradición en escuchar y hablar otros idiomas, lo que nos permite leer, estar y participar en y desde los entrelugares. Aquí comienzan a desplegarse intersticios fantásticos que no podemos rehusarnos a considerar. En mi tema de investigación por ejemplo podría decir que la historia de la visión muestra que, lejos de ser lineal y unívoca, la circulación de las tecnologías y de los dispositivos de visualización se inscribe en cada 
lugar con sustanciales resignificaciones, reapropiaciones y readaptaciones. Estoy investigando precisamente la participación de un país periférico en una cultura visual global.

\section{Entre-Lugar - Considerando suas pesquisas mais recentes, como pensa as relaçóes entre imagens e conhecimentos geográficos?}

Verónica Hollman: Debo admitir que cada día estoy más apasionada por este cruce entre imágenes, visión y conocimiento geográfico. Las imágenes nos exigen, nos desafían, nos provocan. Esto me resulta fascinante. Comencé a trabajar este tema de investigación a partir de mi preocupación por el rol que desempeñaban las imágenes en la enseñanza de la geografía y el interrogante sobre los modos a través de los cuales aprendemos a mirar el amplio universo de imágenes geográficas que se despliegan en los libros escolares y en las clases propiamente dichas. Claro que este protagonismo de las imágenes y de la visión no solo atańe a la práctica de enseńanza de la geografía, sino que también atraviesa otras prácticas propias de la tradición disciplinar. A nivel disciplinar necesitamos continuar y profundizar la problematización del uso que hacemos de las imágenes en nuestras prácticas profesionales, cómo las producimos, cómo las presentamos, cómo las interpretamos. Insisto: no solo en la enseñanza. Probablemente esta invitación a volver a mirar las imágenes, pero de otro modo, pensarlas más como protagonistas y sobre todo pensarlas en relación con la mirada sea una de las contribuciones del giro visual a la disciplina. En este sentido, considero que todavía nos falta avanzar en el diseño y ensayo de estrategias metodológicas para aproximarnos por un lado al análisis de las imágenes, desde su propio código visual; por otro lado, a los modos de mirar las imágenes geográficas y a los impactos de las imágenes en la configuración de una memoria geográfica.

Mi trabajo con imágenes ambientales utilizadas en circuitos que procuran informar (aunque de manera no formal como por ejemplo a través de revistas de circulación masiva o de páginas de Internet) hizo ampliar mi lectura y comenzar a pensar la instrucción visual más allá de lo escolar para entenderla como parte de una cultura visual. En efecto, estamos expuestos a muchas imágenes y cada contexto nos propone modos de mirarlas, entenderlas, significarlas. A mi entender esta línea de trabajo merece seguir consolidándose.

También cada vez me interesa más trabajar con imágenes artísticas y pensar el espacio geográfico desde el arte. Creo que los artistas tienen una sensibilidad para pensar el mundo y que podemos aprender mucho de sus obras. Probablemente también podamos decir mucho sobre sus trabajos y enriquecer nuestra comprensión de los tiempos que estamos viviendo.

Las imágenes también nos muestran que tienen límites. Pienso que precisamente es en ese límite donde residen las múltiples potencias de la imagen. Ese límite, eso no visible, ese vacío ... es precisamente lo que nos permite imaginar. Godard decía que no hay imagen, sino que solo hay imágenes, en plural. Es en ese diálogo, en ese plural, que las imágenes activan la imaginación también para quien la mira. Georges Didí- Huberman, dice que la imaginación supone un trabajo: un tiempo de trabajo de las imágenes. En 
este mundo babélico nos corresponde tomarnos ese tiempo para mostrar las diferencias, las polifonías, lo múltiple de una cultura visual que pareciera presentarse cada día como más homogénea. Creo que somos capaces de proponer montajes potentes, inquietantes que movilicen nuestros imaginarios geográficos, que nos hagan sentir que no podemos renunciar a mirarlos porque nos permiten entrever, releer y sobre todo posicionarnos en estos archivos visuales del mundo cada vez más inaprensibles, cada vez más desgarradores y cada vez más necesarios para interpretar este mundo complejo y babélico.

Recebido em junho de 2017. Aprovado em dezembro de 2017. 